\title{
Development and Evaluation of Orally Disintegrating Tablets of Montelukast Sodium by Direct Compression Method
}

\author{
Muhammad Talha Usmani ${ }^{1}$, Muhammad Harris Shoaib ${ }^{1}$, Muhammad lqbal \\ Nasiri $^{1 *}$, Rabia Ismail Yousuf ${ }^{1}$, Kamran Zaheer ${ }^{2}$ and Kamran Ahmed ${ }^{2}$ \\ ${ }^{1}$ Department of Pharmaceutics, Faculty of Pharmacy, University of Karachi, Karachi, Pakistan, ${ }^{2}$ Department of Pharmaceutics, \\ Faculty of Pharmacy, Hamdard University, Karachi, Pakistan
}

${ }^{*}$ For correspondence: Email: iqbalnasiri@hotmail.com; Tel: +923343377643

\begin{abstract}
Purpose: To design an orally disintegrating montelukast sodium tablet (ODT) that disintegrates in the oral cavity leaving an easy-to-swallow residue especially for pediatric and elderly patients who have difficulty swallowing tablets.

Methods: Two different formulations of montelukast sodium $(5 \mathrm{mg})$ orally disintegrating tablets were designed and manufactured by direct compression method, using microcrystalline (Avicel PH-102), mannitol, sodium bicarbonate, crospovidone and magnesium stearate as key excipients, and with cherry flavor and aspartame as flavor and sweetener, respectively. These formulations were then evaluated using pharmacopoeial and non-pharmacopoeial physical and chemical tests. Dissolution and assay tests were performed using USP apparatus II and ultraviolet (UV) spectrophotometry, respectively. Formulations with better results were further subjected for optimization study using central composite design method.

Results: The results of prototype formulation batch (Trial-02) and the finest optimization formulation batch (FOB-01) reflected the successful development of new formulation of orally disintegrating montelukast sodium $5 \mathrm{mg}$ tablet by direct compression technique. The value of similarity factor $\left(f_{2}>50\right)$, indicating that both formulations have similar drug release profiles. The formulations were further evaluated for three and six months under accelerated conditions to ascertain their stability.

Conclusion: The results obtained demonstrate the suitability of the formulation as an ODT for convenient delivery of montelukast sodium for asthmatic patients. However, clinical studies are required to confirm this.
\end{abstract}

Keywords: Orally disintegrating tablets, Asthma, Disintegration, Dissolution, Montelukast sodium

Tropical Journal of Pharmaceutical Research is indexed by Science Citation Index (SciSearch), Scopus, International Pharmaceutical Abstract, Chemical Abstracts, Embase, Index Copernicus, EBSCO, African Index Medicus, JournalSeek, Journal Citation Reports/Science Edition, Directory of Open Access Journals (DOAJ), African Journal Online, Bioline International, Open-J-Gate and Pharmacy Abstracts

\section{INTRODUCTION}

Historically, the oral route of drug administration has been used most preferably for both conventional as well as for novel drug delivery because of the ease of administration and widespread acceptance by patients [1]. The term "direct compression" is employed to describe the procedure by which tablets are manufactured directly from the powder blends of active pharmaceutical ingredient/s and appropriate excipients [2].

Orally disintegrating tablets (ODTs) offer several advantages over the conventional oral dosage forms particularly in terms of patient compliance 
i.e. convenience and ease of use [3]. One negative aspect of solid oral dosage forms is dysphagia (difficulty in swallowing) and chewing in some patients particularly in geriatric and paediatric patients [4]. Orally disintegrating tablets (ODT) are well established dosage forms that disintegrate in the oral cavity leaving an easy-to-swallow residue. ODT's disintegrate rapidly in saliva without the need of water, within few seconds to minute [5]. Montelukast sodium is a selective, orally active leukotriene receptor antagonist that inhibits the cysteinyl leukotriene CysLT1 receptor. CysLTs receptors have been correlated with the pathophysiology of asthma and allergic rhinitis [6]. It is rapidly absorbed after administration reaching peak plasma concentration $\left(\mathrm{C}_{\max }\right)$ in 3 to $4 \mathrm{~h}$ with a mean bioavailability of $64 \%$ following a $10 \mathrm{mg}$ oral administration. For the $5 \mathrm{mg}$ chewable tablet, the mean $\mathrm{C}_{\max }$ is achieved in 2 to $2.5 \mathrm{~h}$ with a mean bioavailability of $73 \%$ fasting versus $63 \%$ with the standard meal. More than $99 \%$ is bound to plasma proteins with minimal distribution across the blood-brain barrier. Metabolism occurs via liver and excretion occurs almost exclusively in bile with a half-life from 2.7 to $5.5 \mathrm{~h}$ in healthy adults [7].

The objective of the present study was to develop a formulation of montelukast sodium orally disintegrating tablets by direct compression process. For the optimization of the formulation, central composite design was used and statistical evaluation of the formulation using three sigma quality control charts was also performed.

\section{EXPERIMENTAL}

\section{Materials}

The materials used in the formulations with their sources/manufacturer of ingredients are as follows; montelukast sodium (Enaltec Labs (Pvt) Ltd), mannitol (Zhongbao Chemical Corporation Ltd), sodium bicarbonate (Brunner Mond Limited), microcrystalline cellulose (Avicel $\mathrm{PH}$ 102) (Gujrat Microwax Private Limited), crospovidone (ISP Global Technologies ), cherry flavor (Northville Laboratories), aspartame (NutraSweet Company), magnesium stearate (Coin Chemical Industries Co. Ltd). All other chemicals used were of analytical grade.

\section{Experimental design}

Factorial design was used to systematically investigate the product variables that influence product quality. A two level factorial design study was planned using the selected dependent variables and effect on the dependent variable was measured. Based on the relationship between the cause and effect, optimum formula was determined and pilot batches have been manufactured using the optimized formulation. The levels composed of one at the higher side and other at the lower side of the standard / existent value of each independent variable and the data was analyzed using Design-Expert ${ }^{\circledR}$ software (DX9) version 9 (Stat-Ease, Inc. USA) and the analysis are shown in Table 1 . Since we have selected composite points of the fractional composite design therefore eight experimental trial batches were manufactured containing two trials for each independent variable. Formulations of the proposed trials and Formulation Optimization Batches (FOB) are given in Table 3.

\section{Preparation of tablets}

For both Trial-01 and Trial-02 batches, all the ingredients were weighed individually and sifted manually through mesh \# 40 separately. Thereafter, montelukast sodium, mannitol or sodium bicarbonates (mannitol in trial-01 and sodium bicarbonates in trial-02), microcrystalline cellulose and crospovidone were mixed in a poly bag for $5 \mathrm{~min}$ and then cherry flavor and aspartame were added to the blend and mixed well. Magnesium stearate was finally added as lubricant and then mixed for further $5 \mathrm{~min}$. The weight of the tablet was determined as $150 \mathrm{mg}$ and the tablets were compressed (Manesty D3B, England) using a punch and die set to produce square shape tablets with $6.42 \mathrm{~mm}$ length, 6.42 $\mathrm{mm}$ width and $3.77 \mathrm{~mm}$ thickness dimensions. Each tablet contained $5 \mathrm{mg}$ of montelukast sodium (Table 2). Prior to compression, the

Table 1: Factors (independent variables) and factor levels used in factorial composite design

\begin{tabular}{lcc}
\hline Independent variable & $\begin{array}{c}\text { Value in approved trial batch } \\
\text { (factor level used) }\end{array}$ & Levels selected for optimization \\
\hline Tablet weight & $150 \mathrm{mg}$ & $120-170 \mathrm{mg}$ \\
Crospovidone & $4.00 \%$ & $2.00-6.00 \%$ \\
Sodium bicarbonate & $10.67 \%$ & $6.67-14.67 \%$ \\
\hline
\end{tabular}


granules were evaluated for several tests such as angle of repose, compressibility index and hausner's ratio.

\section{Formulation optimization batches (FOB)}

Same procedure followed for all formulation optimization batches (FOB) except, mannitol was replaced by sodium bicarbonate. The weight of tablet was calculated as $150 \mathrm{mg}$ except for FOB01, $120 \mathrm{mg}$ and FOB-02, $170 \mathrm{mg}$ (Table 3). All the other parameters were same as used for trial-01 and trial-02 batches as shown in Table 2.

\section{Evaluation of tablets}

\section{Thickness}

The thickness of the tablets was determined using a Vernier caliper. Twenty tablets from each batch were used, and data were statistically analyzed using control chart.

\section{Weight variation test}

To study weight variation, 20 tablets of each formulation were weighed using an electronic balance (Mettler Toledo), and the test was performed according to the official method.

\section{Hardness}

Hardness of 20 tablets was determined individually, using Hardness tester (Pharma test - Germany) and data were statistically analyzed using control chart.

\section{Friability}

Friability of 20 tablets was determined using Friabilator (Electrolab India and Mettler Toledo).

Percent friability was calculated by using equation 1.

$F(\%)=[(\mathrm{W} 1-\mathrm{W} 2) / \mathrm{W} 1] \times 100$

where, $\mathrm{F}=$ friability, $\mathrm{W} 1=$ Weight of the tablet before testing and $\mathrm{W} 2=$ Weight of the tablet after testing.

\section{In vitro disintegration test}

The in vitro disintegration test was performed on each formulation using USP disintegration apparatus (Pharma test, Germany). European Pharmacopoeial method was followed for all formulations. Six tablets of each formulation were tested for disintegration. Distilled water was used as disintegration medium at $37 \pm 2{ }^{\circ} \mathrm{C}$ temperature. The time taken until no material

Table 2: Composition of prototype formulations

\begin{tabular}{|c|c|c|}
\hline Ingredient & Trial-01 (mg/tab) & Trial-02 (mg/tab) \\
\hline Montelukast Sodium & $5.20^{*}$ & $5.20^{*}$ \\
\hline Mannitol & 70.000 & - \\
\hline Microcrystalline Cellulose & 48.800 & 116.80 \\
\hline Sodium Bicarbonate & - & 16.00 \\
\hline Crospovidone & 20.000 & 20.000 \\
\hline Aspartame & 2.000 & 2.000 \\
\hline Cherry Flavour & 2.000 & 2.000 \\
\hline Magnesium Stearate & 2.000 & 2.000 \\
\hline Total & 150.00 & 150.00 \\
\hline
\end{tabular}

Table 3: Formulations of optimization batches

\begin{tabular}{lccccccc}
\hline Ingredient & $\begin{array}{c}\text { Trial-02 } \\
\mathbf{m g} / \mathbf{t a b}\end{array}$ & $\begin{array}{c}\text { FOB-01 } \\
\mathbf{m g} / \mathbf{t a b}\end{array}$ & $\begin{array}{c}\text { FOB-02 } \\
\mathbf{m g} / \mathbf{t a b}\end{array}$ & $\begin{array}{c}\text { FOB-03 } \\
\mathbf{m g} / \mathbf{t a b}\end{array}$ & $\begin{array}{c}\text { FOB-04 } \\
\mathbf{m g} / \mathbf{t a b}\end{array}$ & $\begin{array}{c}\text { FOB-05 } \\
\mathbf{m g} / \mathbf{t a b}\end{array}$ & $\begin{array}{c}\text { FOB-06 } \\
\mathbf{m g} / \mathbf{t a b}\end{array}$ \\
\hline Montelukast sodium & $5.20^{*}$ & $5.20^{*}$ & $5.20^{*}$ & $5.20^{*}$ & $5.20^{*}$ & $5.20^{*}$ & $5.20^{*}$ \\
Microcrystalline cellulose & 116.800 & 92.410 & 133.080 & 122.790 & 110.790 & 119.800 & 113.800 \\
Sodium bicarbonate & 16.000 & 12.804 & 18.139 & 10.005 & 22.005 & 16.000 & 16.000 \\
Crospovidone & 6.000 & 4.800 & 6.800 & 6.000 & 6.000 & 3.000 & 9.000 \\
Aspartame & 2.000 & 1.596 & 2.261 & 2.000 & 2.000 & 2.000 & 2.000 \\
Cherry flavour & 2.000 & 1.596 & 2.261 & 2.000 & 2.000 & 2.000 & 2.000 \\
Magnesium Stearate & 2.000 & 1.596 & 2.261 & 2.000 & 2.000 & 2.000 & 2.000 \\
\hline Total weight $\mathbf{( m g )}$ & $\mathbf{1 5 0 . 0 0}$ & $\mathbf{1 2 0 . 0 0}$ & $\mathbf{1 7 0 . 0 0}$ & $\mathbf{1 5 0 . 0 0}$ & $\mathbf{1 5 0 . 0 0}$ & $\mathbf{1 5 0 . 0 0}$ & $\mathbf{1 5 0 . 0 0}$ \\
\hline
\end{tabular}


from any of the tablets was left on the mesh was recorded in seconds.

\section{Assay of montelukast sodium}

Assay of drug was carried out using average weight of the crushed tablets equivalent to the weight of single tablet into $50 \mathrm{ml}$ volumetric flask. Methanol $(25 \mathrm{ml})$ was added,, sonicated for 2 min and made up the volume with same solvent and mixed thoroughly for $15 \mathrm{~min}$. UV absorbance of the filtered solution was measured using UVVisible spectrophotometer [UV 2450, Shimadzu Corporation, Japan] at $285 \mathrm{~nm}$ ( $\lambda$ max). Standard working solution was prepared by weighing accurately $25 \mathrm{mg}$ of montelukast sodium into a $100 \mathrm{ml}$ volumetric flask following the similar procedure for sample solution and dilution procedure. From the absorbance of the sample solution and standard solution, the amount of drug in the percentage assay of ODTs was calculated.

\section{In vitro dissolution studies}

In vitro dissolution studies were performed for the tablets $(n=6)$ using USP dissolution apparatus II (paddle type), at $50 \mathrm{rpm}$, thermostatically maintained at temperature $37 \pm 0.5{ }^{\circ} \mathrm{C}$, with dissolution medium of $500 \mathrm{ml}$ having $0.2 \%$ of sodium lauryl sulphate in it. Dissolution study was carried out for duration of $30 \mathrm{~min}$ with sampling interval of 5 minutes, 10 minutes, 20 minutes, and 30 minutes. The absorbance of both test solution and standard solution at 285 $\mathrm{nm}$ taking $0.2 \%$ Sodium Lauryl Sulphate as blank.

\section{Stability studies}

The product was packed in Alu/Alu blister and was stored according to storage condition recommended for accelerated conditions in $\mathrm{ICH}$ guidelines. Stability condition used were, temperature $40 \pm 2{ }^{\circ} \mathrm{C}$ and relative humidity $75 \pm$ $5 \% \mathrm{RH}$. Accelerated study was conducted for a period of 3 and 6 months for the stability indicating parameters such as appearance, weight variation, hardness, disintegration, dissolution and assay.

\section{Statistical analysis}

The cumulative percentage of drug Montelukast sodium release from the dosage form $(n=6)$ in the dissolution medium was tested for a statistical significance by using of One-way ANOVA test between the two values. The level of significance was set at $p<0.05$.

\section{RESULTS}

\section{Physicochemical properties of compressed ODTs}

All the formulations were evaluated for weight variation, hardness, friability, thickness, disintegration and assay and their results are shown in Table 4. From the evaluation parameters, it was observed that weight and thickness of all batches complied with the desired specification except FOB-02 for which thickness was high but was within limits of $\pm 5 \%$. Hardness of all formulations was between 8.45 and $15.85 \mathrm{~kg} / \mathrm{cm}^{2}$ and this was found satisfactory and within desired specification. The friability test results of all formulations were $<1 \%$ and it was also found to be within the limits specified in the B.P.

Assay determination was done using UV spectrophotometer for the detection of montelukast sodium at a wavelength of $285 \mathrm{~nm}$. On the basis of pharmaceutical assay results of montelukast in all formulations was > $98 \%$ (Table 4). It was concluded that concentrations of active ingredient in tablets of all three formulations (FOB-01, FOB-03, and FOB-06) of montelukast orally disintegrating tablet was found satisfactory.

Table 4: Physicochemical characteristics of ODT tablets

\begin{tabular}{|c|c|c|c|c|c|c|}
\hline $\begin{array}{l}\text { Batch } \\
\text { code }\end{array}$ & $\begin{array}{c}\text { Thickness }^{* *} \\
(\mathrm{~mm})\end{array}$ & $\begin{array}{l}\text { Hardness }{ }^{* *} \\
\left(\mathrm{Kg} / \mathrm{cm}^{2}\right)\end{array}$ & $\begin{array}{c}\text { Weight Variation } \\
\text { test }^{* *}(\mathrm{mg})\end{array}$ & $\begin{array}{c}\text { Friability** } \\
(\%)\end{array}$ & $\begin{array}{c}\text { Disintegration } \\
\text { test }^{* * *}(s)\end{array}$ & $\begin{array}{l}\text { Assay* } \\
(\%)\end{array}$ \\
\hline Trial-01 & $3.79 \pm 0.03$ & $14.54 \pm 1.02$ & $150.45 \pm 1.8$ & $0.06 \pm 0.02$ & $40 \pm 1.4$ & $101.89 \pm 0.02$ \\
\hline Trial-01 & $3.78 \pm 0.02$ & $9.77 \pm 1.24$ & $149.85 \pm 2.1$ & $0.11 \pm 0.03$ & $10 \pm 1.6$ & $100.58 \pm 0.03$ \\
\hline FOB-01 & $3.07 \pm 0.01$ & $9.35 \pm 0.17$ & $120.55 \pm 1.3$ & $0.04 \pm 0.02$ & $08 \pm 2.6$ & $99.63 \pm 0.02$ \\
\hline FOB-02 & $3.79 \pm 0.01$ & $15.85 \pm 0.71$ & $169.90 \pm 2.7$ & $0.17 \pm 0.03$ & $35 \pm 2.2$ & $98.76 \pm 0.02$ \\
\hline FOB-03 & $3.74 \pm 0.03$ & $10.28 \pm 0.99$ & $150.10 \pm 0.8$ & $0.08 \pm 0.01$ & $22 \pm 1.4$ & $99.26 \pm 0.13$ \\
\hline FOB-04 & $3.75 \pm 0.02$ & $8.79 \pm 0.50$ & $150.20 \pm 2.1$ & $0.12 \pm 0.03$ & $05 \pm 1.3$ & $98.16 \pm 0.03$ \\
\hline FOB-05 & $3.77 \pm 0.02$ & $8.45 \pm 0.54$ & $150.25 \pm 1.0$ & $0.06 \pm 0.02$ & $14 \pm 1.3$ & $99.25 \pm 0.04$ \\
\hline FOB-06 & $3.74 \pm 0.02$ & $8.94 \pm 0.59$ & $150.25 \pm 1.7$ & $0.05 \pm 0.05$ & $10 \pm 1.6$ & $99.61 \pm 0.15$ \\
\hline
\end{tabular}

${ }^{*}$ All values are expressed as mean $\pm S D, n=3 ;{ }^{* *}$ All values are expressed as mean $\pm S D, n=20 ;{ }^{* * *}$ All values are expressed as mean $\pm S D, n=6$ 


\section{In vitro disintegration test}

The in vitro disintegration time for all the compressed tablets was determined and results of all formulations are given in Table 4.

The time for disintegration of orodispersible tablets (orally disintegrating tablets) is generally $<1$ min and the actual time that patient can experience ranges from 5 to $30 \mathrm{~s}$.

\section{In vitro dissolutions studies}

The time points were selected based on the FDA recommendation for most orally disintegrating tablets. In vitro dissolution studies showed that more than $50 \%$ of the drug was released from all the formulations within $5 \mathrm{~min}$. From in vitro dissolution data, it was observed that an average of more than $75 \%$ of montelukast, released in the dissolution medium from all the formulations within 15 min indicates that the tablet complies as per EP specifications, that is, not less than 70 $\%$ in 30 min shown in Figure 1. This assures quick delivery of active ingredient for systemic absorption.

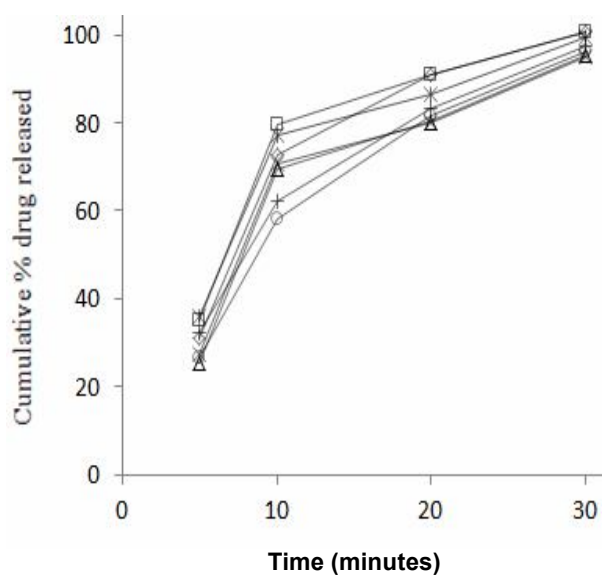

Figure 1: Cumulative drug release profile of all developed batches (Note: Trail-02 $=\diamond$ FOB-01 $=\square$, FOB-02 $=\Delta$, FOB-03 $=\times$, FOB-04 $={ }^{*}$, FOB-05 $=$, FOB-06 = t) $(n=6)$

\section{Stability}

The compressed tablets were stored in an aluminum blister packs in a chamber controlled at $40 \pm 2{ }^{\circ} \mathrm{C}$ and relative humidity $75 \pm 5 \%$ for three and six months, and then the content of montelukast was determined along with its dissolution as per $\mathrm{ICH}$ guidelines. All parameters found satisfactory which concluded that active ingredient is stable in the formulation.

\section{DISCUSSION}

Orally disintegrating tablets (ODTs) offer several advantages over the conventional oral dosage forms particularly in terms of patient compliance i.e. convenience and ease of use. Over the past decade, considerable progresses in the formulation of ODTs have been accomplished in academic research and industry that resulted in the rising of a large number of patents [3].

Any dosage form that disintegrates or dissolves rapidly offer more compliance for pediatric and geriatric patients having difficulty in swallowing, and in conditions where potable water is not readily available. For such kind of formulations, the minute quantity of fluid such as saliva is typically enough for quick disintegration of tablet in mouth. This helps the drug to be readily available for dissolution and subsequent absorption into the blood through the blood vessels of either the oral cavity or from the blood vessels of the stomach or intestine upon being ingested [8]. Direct compression is a major manufacturing process employed in pharmaceutical technology. With this process, granulating the powder mass before tableting is not required which makes it a very efficient process with no complex unit operation involved. In order to describe a new excipent, the research on its physicochemical properties like flowability, physical form (crystallinity) and water content is considered crucial as these directly effects the properties of final dosage form [9].

The aim of the research study was to design and develop a new formulation of orally disintegrating montelukast $5 \mathrm{mg}$ tablet by adopting the approach of using conventional process of direct compression, and by choosing the conventional excipients rather than any novel one so that the final dosage form is manufactured in much simpler and cost effective manner. This will facilitate the availability of economical and patient compliant product for efficient pharmaceutical therapy. In present study, all of the required characteristics of quality product were considered in order to ensure that designed product must meet the expectation of official compendia, pharmaceutical manufacturers and customers in terms of identity, efficacy and cost effectiveness.

Initially two formulations were proposed for product development. Based upon the physical and chemical characteristics of the product, it was concluded that Trial-02 is more appropriate as it takes less time to disintegrate than Trial-01 because quick disintegration is the core objective of ODTs. Based on the obtained results, 
formulation optimization activity was planned for Trial-02, taking theoretical compression weight, level of sodium bicarbonate and level of crospovidone as independent variable while friability, hardness and dissolution as their response (dependent variable). The results obtained from the study were statistically analyzed and different evaluation approaches were made in order to obtain quality product at minimum cost and time period. Afterwards the new formulation was subjected for accelerated stability studies to evaluate the integrity of formulation throughout the shelf life of the product.

In the developed formulations of ODTs, the amount of active ingredient was minute therefore the performance of tablet was extensively dependent upon the used excipients. Microcrystalline cellulose was used as diluent which showed excellent compressibility. The core excipients were sodium bicarbonate and crospovidone because of their direct effect on the disintegration of compression tablets in the mouth cavity. Remaining excipients included cherry flavor, aspartame and magnesium stearate. Results obtained from trial and optimization batches data clearly illustrate the significant role of crospovidone and sodium bicarbonate in the integrity of the formulation.

\section{CONCLUSION}

By employing commonly available pharmaceutical excipients such as mannitol, sodium bicarbonate, crospovidone and microcrystalline cellulose, a fast disintegrating tablet of montelukast sodium can be developed which can be commercialized. The developed formulation of montelukast sodium ODT should lead to improved efficacy, rapid onset of action, better patient compliance.

\section{ACKNOWLEDGEMENT}

The authors wish to express their thanks to Getz Pharma (Pvt) Ltd, Pakistan for providing, free of charge, the samples used in this study. The authors acknowledge Department of Pharmaceutics, Faculty of Pharmacy, University of Karachi for providing facilities for this work.

\section{REFERENCES}

1. Kewal K. Jain, editor. Drug delivery systems, Method in molecular biology. Vol 437, Totowa, NJ: Humana press; 2008; $p 2$.

2. Shangraw RF. Direct Compression Tableting, Swarbrick J, Boylan JC, Eds. Encyclopedia of Pharmaceutical Technology. Vol 4, 1st edn, USA: Marcel Dekker; 1988; pp 85-160.

3. Al-Husban FA, El-Shaer AM, Jones RJ, Mohammed AR. Recent patents and trends in orally disintegrating tablets. Recent Pat Drug Deliv Formul. 2010; 4(3): 178-197.

4. Habib W, Khankari RK, Hontz J. Fast dissolve drug delivery systems. CritRevTherDrugCarrierSyst. 2000; 17: 61-72.

5. Robert OW. David RT, Jason TM. Advanced drug formulation design to optimize therapeutic outcomes, Drugs and Pharmaceutical Sciences. Vol 172, Yew York: Informa-Heatlhcare; 2007; p 293.

6. Kanoaka Y, Boyce J. Cysteinyl leukotrienes and their receptors: cellular distribution and function in immune and inflammatory responses. J Immunol 2004; 173: 1503-1510.

7. Singulair (montelukast sodium). Product information. Merck \& Co WS NJ. (Cited 2009 April 20) Available from: http://www.singulair.com/singulair/shared/docu ments/english/singulair_prescribing_infopdf 2006.

8. Mutasem M, Rawas-Qalaji F, Estelle RS, Keith JS. Fastdisintegrating sublingual tablets: Effect of epinephrine load on tablet characteristics. AAPS PharmSciTech. 2006; 7(2): E72-E78.

9. Hauschild K, Picker-Freyer KM. Evaluation of a new coprocessed compound based on lactose and maize starch for tablet formulation. AAPS PharmSci. 2004; 26: 6(2): e16. 